\title{
PERANCANGAN FORUM DISKUSI MOBILE ONLINE LEARNING
}

\author{
Agus Putranto \\ Computer Science Department, School of Computer Science, Binus University \\ Jl. K.H. Syahdan No. 9, Palmerah, Jakarta Barat 11480 \\ aputra@binus.edu
}

\begin{abstract}
The utilization of e-learning can improve effectiveness and flexibility of learning. One important activities e-learning feature is a discussion forum. Communication between educators and students in class will be more effective if combined with communication through a discussion forum. Binus Online Learning is selected as a place of research. Binus Online Learning is a program of Bina Nusantara University that offers online study activities, which most of the students are invited to have self study activities. The aim of this research is to do requirement analysis and then to design a forum discussion called M-learning for Binus Online Learning so that it will be beneficial for the students that they can easily use the faster access. In this research, used are data collection through surveis, and analysis based on are literature study and the current systems, while rich picture and user interface are used for design. The results obtained are some features for the mobile learning discussion forum.
\end{abstract}

Keywords: learning, mobile learning, discussion forum

\begin{abstract}
ABSTRAK
Pemanfaatan e-learning dapat meningkatkan efektivitas dan fleksibilitas pembelajaran. Salah satu fitur e-learning yang penting dalam kegiatan belajar mengejar adalah forum diskusi. Dengan forum diskusi, komunikasi antar dosen dan mahasiswa akan lebih efektif, karena kegiatan belajar di kelas saja tidak akan cukup untuk mahasiswa. Sebagai tempat penelitian, penulis memilih Binus Online Learning, yaitu suatu program perkuliahan secara online dari Universitas Bina Nusantara, di mana para mahasiswanya lebih banyak diajak untuk belajar secara mandiri. Tujuan penelitian ini ialah melakukan analisis kebutuhan dan kemudian menentukan rancangan pada forum diskusi M-Learning pada Binus Online Learning agar dapat mudah digunakan dan cepat dalam pengaksesannya. Dalam penelitian ini digunakan metode pengumpulan data (dengan melakukan survei), dan metode analisis yang terbagi atas studi kepustakaan, dan analisis sistem berjalan. Sedangkan perancangan menggunakan Rich Picture dan rancangan layar. Hasil yang dicapai ialah fitur-fitur forum diskusi Mobile Learning.
\end{abstract}

Kata kunci: pembelajaran, forum diskusi, mobile learning 


\section{PENDAHULUAN}

Saat ini banyak perguruan tinggi terus berinovasi untuk menjadi membuat sistem pembelajaran yang semakin mudah, cepat dan efektif. E-learning dapat menjadi salah salah satu cara yang diadopsi oleh banyak perguruan tinggi saat ini. E-learning adalah suatu metode pembelajaran dan pelatihan bagi mahasiswa yang memanfaatkan teknologi informasi untuk mengirim, mendukung, meningkatkan pembelajaran, dan melaporkan hasil pembelajaran.

E-learning digunakan untuk dapat menyampaikan materi pelajaran atau pelatihan tanpa adanya batasan tempat dan waktu, yang pada akhirnya akan meningkatkan kualitas dari proses pelatihan tersebut. Untuk mencapai kualitas dari pelatihan juga dibutuhkan kolaborasi dari berbagai jenis e- learning baik yang bersifat synchronous maupun asynchronous (Tsai, 2010). E-Learning mengacu pada semua kegiatan pelatihan yang menggunakan media elektronik atau teknologi informasi (Effendi dan Zhuang, 2005).

Pemanfaatan e-learning dapat meningkatkan efektivitas dan fleksibilitas pembelajaran. Di samping itu materi dapat diperkaya melalui berbagai macam materi belajar termasuk multimedia yang interaktif untuk mendukung proses belajar mengajar. Dengan memanfaatkan e-learning, dosen dapat dengan mudah mengunggah materi kuliah, memberikan tugas untuk evaluasi, serta memonitor dan menjalin komunikasi dengan mahasiswa melalui teknologi berbasis web.

Perkembangan teknologi mobile juga berkembang dengan sangat pesatnya dan perangkat mobile-nya sendiri sudah bisa didapat dengan harga yang murah. Perangkat mobile sendiri memungkinkan pengaksesan suatu informasi kapan dan di mana saja dengan menggunakan menggunakan perangkat mobile, seperti handphone, PDA, smartphone, atau yang sedang booming sekarang ini yaitu tablet PC.

Pemanfaatan internet untuk mendukung program belajar mengajar, sudah mulai dilaksanakan di lingkungan Binus University sejak tahun 1998. Sejak 2008 ini, Binus University mulai menawarkan program Online Learning bagi masyarakat yang memiliki kendala untuk mengikuti perkuliahan secara regular. Dengan menawarkan fleksibilitas melalui metode belajar yang tidak terikat dengan tempat dan waktu tapi tetap fokus sehingga menjamin kualitas lulusan program Online Learning ini akan sama dengan lulusan yang berkuliah secara regular. Online Learning menggunakan LMS (learning management system) yang terintegrasi untuk membangun jaringan interaksi antara mahasiswa dengan mahasiswa, mahasiswa dengan dosen dan mahasiswa dengan pembimbing akademis. Dengan demikian mahasiswa online learning dipastikan mempunyai kualitas yang sama dengan mahasiswa yang melakukan sistem perkuliahan pada umumnya. Melalui media online, pembelajaran dapat dilakukan tanpa ada batasan waktu dan tempat, sehingga mahasiswa online akan berasal dari berbagai daerah dan negara yang akan dipandu oleh dosen-dosen Binus yang tidak hanya berada di Jakarta tetapi juga yang sedang berada di luar negeri. Forum diskusi sebagai media komunikasi antara para mahasiswa dan dosen juga sudah digunakan pada LMS (learning management system) Binus Online Learning.

Semakin kuatnya keinginan untuk belajar membuat mahasiswa merasakan kesulitan untuk mengakses komputer dalam keseharian, karena komputer harus dihidupkan terlebih dahulu dan tidak selalu membawa komputer. Sehingga para mahasiswa dan dosen merasakan kesulitan untuk mengakses forum diskusi jika harus menggunakan komputer. Forum merupakan sebuah media berdiskusi di mana dibagi menjadi topik-topik diskusi yang berbeda (Watkins, 2006). Karena smartphone atau mobile phone selalu dibawa kemanapun para mahasiswa dan dosen pergi, penggunaan diskusi forum mobile akan menjadi salah satu sarana yang penting bagi perkembangan pembelajaran mahasiswa ke depannya. 
Mobile Learning atau M-Learning sering didefinisikan sebagai E-Learning melalui perangkat komputasi mobile (Andy, 2007). Sedangkan Ally et al. (2004) mendefinisikan m-learning merupakan penyampaian bahan pembelajaran elektronik pada alat komputasi mobile agar dapat diakses dari mana saja dan kapan saja. Pada umumnya, perangkat mobile berupa telepon seluler digital dan PDA. Andy (2007) menjelaskan bahwa di luar keterbatasan yang dimiliki oleh m-learning, sistem ini memiliki beberapa kelebihan dibandingkan dengan sistem e-learning, yaitu: portabilitas, mendukung pembelajaran, meningkatkan motivasi, jangkauan lebih luas serta pembelajaran tepat waktu. Ia juga menjelaskan perbedaan yang paling besar antara e-learning dan m-learning adalah dalam hal karakterisktik hardware/software perangkat. Akses ke web melalui perangkat mobile, dengan ukuran layar kecilnya, telah menjadi masalah yang menarik bagi banyak peneliti. Oleh sebab itu, penelitian ini akan membahas mengenai perancangan forum diskusi mobile yang dibutuhkan oleh mahasiswa yang mengikuti pembelajaran secara online learning.

Agar penelitian ini tidak melebar maka penulis memberikan tiga batasan. Pertama, penelitian menggunakan studi kasus pada Binus Online Learning. Kedua, dalam menganalisis e-learning yang berjalan, penelitian dimulai dari peserta yang terdaftar aktif sebagai mahasiswa. Dan terakhir, fitur Forum Diskusi Mobile yang akan dirancang hanya untuk para mahasiswa dan belum mencangkup dosen.

Tujuan dari penulisan ini yaitu melakukan analisis terhadap e-learning dari sistem yang sedang berjalan, dan merancang forum diskusi mobile learning. Selain tujuan, manfaat dari penulisan ini adalah meningkatkan mobilitas mahasiswa melalui mobile learning melalui mobile phone, dan mempermudah pengembangan aplikasi mobile learning,

\section{METODE}

Pada penelitian kali ini dilakukan analisis terhadap sistem berjalan pada sistem e-learning dan forum diskusi. Selain itu, dilakukan pula survei terhadap lebih dari 10\% total mahasiswa Binus Online Learning. Survei diadaakan pada saat sedang diadakannya perkuliahan onsite atau belajar di ruang kelas sebelum melakukan ujian pada pertemuan ke-10, sample yang diambil sebanyak 72 orang, dengan kelas yang ambil secara acak serta jurusan yang acak juga, dengan mahasiswa aktif sekarang ini adalah sebanyak 670 orang. Dari hasil survei dilakukan analisis mengenai kebutuhan dan penggunaan forum diskusi mobile.

\section{HASIL DAN PEMBAHASAN}

\section{Analisis Sistem Berjalan}

\section{Sistem Berjalan E-Learning}

Pertama, bagian Content Development Staff akan menguploadkan konten materi pembelajaran ke dalam database LMS Binus Online Learning. Setelah itu dosen akan memberikan topik diskusi dan tugas untuk setiap pertemuan, (biasanya batas waktu 1 pertemuan adalah 1 minggu). Kemudian jika ada tugas yang perlu direvisi, maka dosen akan menginformasikan kepada mahasiswa melalui Discussion Forum. Topik diskusi dan tugas tersebut dapat diakses oleh mahasiswa melalui LMS dan Discussion Forum. Topik diskusi dan tugas tersebut nantinya akan dikerjakan oleh mahasiswa dan mengumpulkannya melalui LMS. Kemudian jika terjadi revisi, maka mahasiswa wajib untuk memperbaikinya sesuai dengan batas waktu yang diberikan oleh dosen. Dalam Discussion Forum, 
Dosen akan menanggapi jawaban topik diskusi yang diberikan oleh setiap mahasiswa, dan jika ada pertanyaan, maka dosen juga wajib untuk menanggapinya. Dan untuk tugas yang diberikan, maka dosen akan membuat penilaian.

Bagian Lecturer Services \& Class Monitoring Staff bertugas untuk mengecek rasio partisipasi mahasiswa ataupun dosen sendiri, untuk mengetahui bahwa keaktifan kelas berjalan dengan baik. Bagian ini pula yang akan membuat sebuah laporan yang berisikan rasio keaktifan dosen yang mengajar di setiap kelasnya, dan laporan tersebut akan dibuat setiap bulannya, memberikan laporan keaktifan dosen dan mahasiswa tersebut kepada Deputy Director yang bertugas untuk memastikan bahwa kelas sudah berjalan dengan baik. Deputy Director akan memberikan peringatan atau teguran bagi dosen yang tidak aktif dalam kegiatan pembelajaran di kelas.

Dosen akan memberikan soal ujian kepada Bagian Thesis \& Graduation Staff. Kemudian bagian Thesis \& Graduation Staff akan melakukan penjadwalan ujian yang akan dilakukan oleh mahasiswa dan melakukan ujian berdasarkan soal ujian yang diberikan oleh dosen mata kuliah. Mahasiswa akan datang ke Binus untuk mengikuti ujian, baik itu UTS maupun UAS dan mengerjakan soal ujian. Bagian Thesis \& Graduation Staff akan memberikan jawaban ujian yang dikerjakan oleh mahasiswa kepada desen yang mengajarnya. Setelah Dosen selesai melakukan penilaian terhadap hasil ujian mahasiswanya, maka Dosen akan mengupload nilai mahasiswa ke dalam database melalui LMS.

Mahasiswa dapat mengadukan keluahan-keluhan yang didapatnya di kelas maupun dengan dosen dengan menuliskannya melalui Public Forum, yang di mana Public Forum ini berfungsi sebagai wadah untuk melakukan pertanyaan ataupun keluhan mengenai dunia pembelajaran. Keluhan ataupun pertanyaan ini akan dapat diakses oleh Bagian Student Services \& Helpdesk Staff. Bagian Student Services \& Helpdesk Staff akan memberikan tanggapan terhadap keluahan dan pertanyaan yang diajukan oleh mahasiswa.

Di bawah ini adalah rich picture dari sistem e-learning yang sedang berjalan (Gambar 1).



Gambar 1. Rich picture sistem berjalan e-learning. 


\section{Sistem Berjalan Forum Diskusi}

Mahasiswa login ke Forum melalui Komputer/Laptop. Dosen juga dapat login ke Forum melalui Komputer/Laptop. Server akan memverifikasi username dan password mahasiswa/dosen berdasarkan database Binus Online Learning.

Kemudian data-data (matapelajaran, materi, dan servis-servis maupun informasi perkuliahan[disini difokuskan langsung kepada forum dan materi, dan juga diamsumsikan mahasiswa/I sudah memilih mata pelajaran]) akan dikirimkan ke komputer. Mahasiswa bisa mengunduh materi masing-masing pertemuan.

Mahasiswa memilih empat Forum yang ingin dimasuki (Class Room, Team Room, Meet The Lecture, dan Personal Room). Dalam Class Room, dosen membuat topik pembahasan untuk ditanggapi oleh sesama mahasiswa. Mahasiswa juga dapat membuat topik pembahasan untuk ditanggapi oleh dosen atau oleh sesama mahasiswa. Sesama Mahasiswa memberikan tanggapan dan pembahasan topik yang telah diberikan oleh dosen dan sesama mahasiswa. Dosen juga memberikan tanggapan dari pertanyaan atau topik yang diberikan oleh mahasiswa. Dalam Team Room, satu mahasiswa memberikan tanggapan dan bahasan untuk anggota tim yang lainnya. Sesama Mahasiswa satu kelompok mengakses bahasan yang diberikan oleh teman sekelompoknya. Anggota tim yang lain memberikan tanggapan dari bahasan yang diberikan oleh teman kelompok sendiri. Dalam meet the lecture, mahasiswa memberikan pertanyaan yang sifatnya pribadi untuk dosen yang mau dihubunginya melalui Meet The Lecturer Forum. Dosen mengakses pertanyaan dari Meet The Lecturer Forum. Dosen memberikan tanggapan dan jawaban ke Mahasiswa dari pertanyaan mahasiswa dari Meet The Lecturer Forum. Dalam Personal Room, mahasiswa memberikan tanggapan dan pembahasan topik antar mahasiswa dikelas itu sendiri. Mahasiswa mendapatkan tanggapan dan pembahasan topik antar mahasiswa dikelas itu sendiri.

Data dari masing-masing Forum yang dipilih akan ditampilkan ke dalam komputer. Data forum di-update ke database Binus Online Learning. Di bawah ini adalah rich picture dari sistem forum diskusi yang sedang berjalan (Gambar 2).

\section{Hasil Survei}

Pertanyaan pertama, mengenai sistem operasi handphone yang digunakan mahasiswa Binus Online Learning saat ini. Hasil ini untuk mengetahui platform handphone yang sedang digunakan sekarang ini. Saat ini banyak yang menggunakan Blackberry, tetapi sistem operasi handphone yang mahasiswa anggap akan berkembang pesat ke depannya dan yang akan digunakan ke depannya adalah sistem operasi android.

Kedua, mengenai waktu penggunaan ponsel oleh mahasiswa Binus Online Learning pada setiap harinya, di mana mahasiswa menggunakan ponsel smartphone, seperti BlackBerry, Android, IOS dan lain-lain. Hasilnya adalah penggunaan kurang dari 5 jam perharinya.

Ketiga, kebutuhan discussion forum. Hasil menunjukkan bahwa $89 \%$ membutuhkan forum diskusi mobile. Oleh karena itu sudah pasti familiar dengan aplikasi-aplikasi smartphone.

Berdasarkan data penggunaan discussion forum, dengan aturan mahasiswa minimal dua kali posting per minggu, didapat total minimal 20 kali per mata kuliah, tiga kali posting per mata kuliah, sedangkan meet the lecturer dan Personal Room tidak ada keharusan. Berdasarkan data yang diperoleh, $80 \%$ pemakaian ada di Class Room, $12 \%$ ada di Team Room, $4 \%$ ada di meet the lecturer, dan hampir $4 \%$ ada di Personal Room. 
Untuk menentukan apakah materi yang digunakan, penulis merujuk pada pendapat Andy (2007) yang menyatakan bahwa ukuran layar kecilnya menjadi masalah yang menarik. Oleh karena itu, fitur lecturer note ditiadakan atau ditolak, karena lecturer note itu bertipe file pdf yang berbentuk picture, sehingga tulisannya akan pecah pada saat dilakukan zooming. Namun, agar tetap dapat diakses dan diunduh melalui aplikasi ini, materi pembelajaran dibuat berbentuk powerpoint, sehingga masih nyaman untuk digunakan untuk belajar melalui mobile.

Untuk memastikan operating sistem mobile yang akan dibahas lebih lanjut, penulis mendapatkan data dari StatCounter Global Stat, (statistik penggunaan operating sistem), di mana Android ada kecenderungan meningkat dari 2010 - 2012 (Gambar 3). Hal ini dapat memperkuat survei di atas, bahwa pengguna Android makin meningkat.

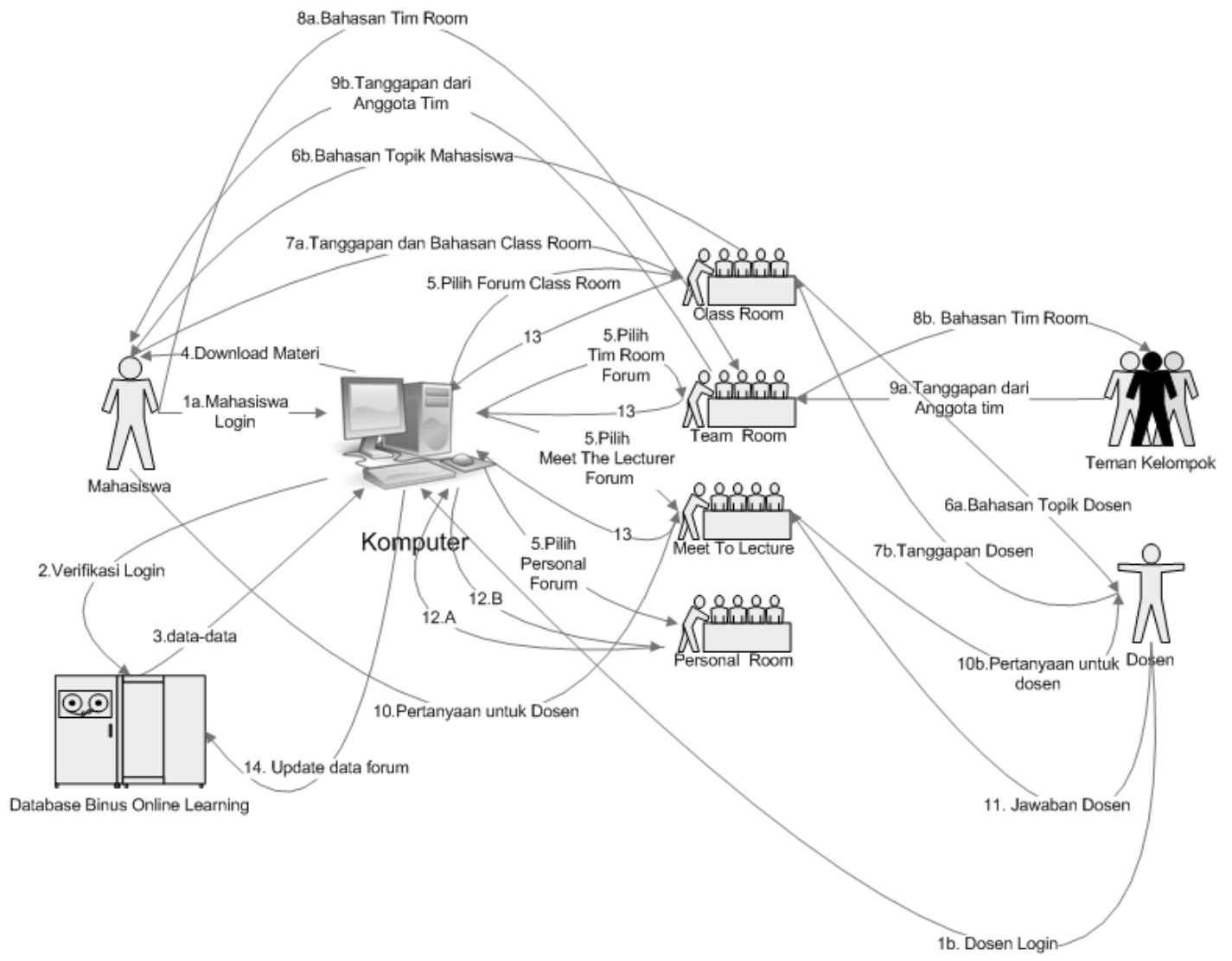

Gambar 2. Rich Picture sistem forum diskusi yang sedang berjalan.

Catatan: 12.A Tanggapan dan Bahasan Personal Room

12.B Tanggapan dan Bahasan Personal Room

\section{Rancangan}

\section{E-Learning Usulan}

Aplikasi Android Mobile Phone pada Binus Online Learning berfungsi untuk berdiskusi dan mengunduh materi-materi pertemuan. Dimulai dari Mahasiswa Login, memilih mata pelajaran, memilih forum, dan memberikan tanggapan, bahasan, topik, pertanyaan,dll. Aplikasi ini juga dapat memberikan reminder terhadap perubahan yang terjadi didalam forum jika ada topik atau bahasan atau tanggapan baru muncul. 
Penulis menjelaskan bahwa perubahan ataupun usulan mobile discussion forum terletak di tengah dengan ada tambahan gambar lingkaran. Urutan penjelasan dimulai dari proses seperti rich picture sistem berjalan, kemudian dilanjutkan penjelasan mengenai mobile discussion forum terletak pada paragraph terakhir.

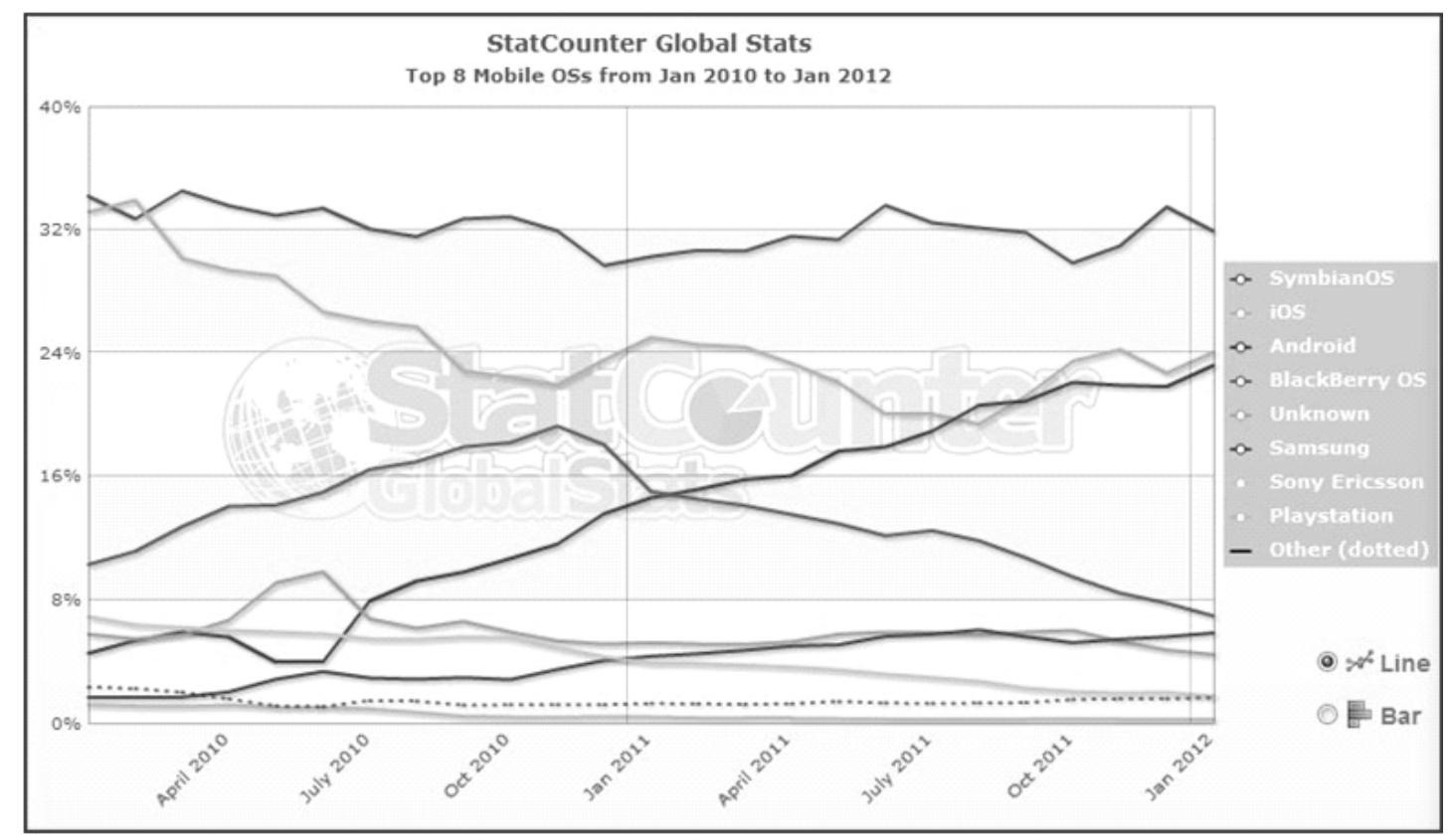

Gambar 3. Statistik penggunaan operating sistem (StatConter Global Stats).

Dosen akan memberikan topik diskusi dan tugas untuk setiap pertemuan, (biasanya batas waktu satu pertemuan adalah satu minggu). Kemudian jika ada tugas yang perlu direvisi, dosen akan menginformasikan kepada mahasiswa melalui Discussion Forum. Topik diskusi dan tugas tersebut dapat diakses oleh mahasiswa melalui LMS dan Discussion Forum. Topik diskusi dan tugas tersebut nantinya akan dikerjakan oleh mahasiswa dan mengumpulkannya melalui LMS. Kemudian jika terjadi revisi, mahasiswa wajib untuk memperbaikinya sesuai dengan batas waktu yang diberikan oleh dosen. Dosen akan menanggapi jawaban topik diskusi yang diberikan oleh setiap mahasiswa, dan jika ada pertanyaan, dosen juga wajib untuk menanggapinya. Dan untuk tugas yang diberikan, dosen akan membuat penilaian. Bagian Lecturer Services \& Class Monitoring Staff bertugas untuk mengecek rasio partisipasi mahasiswa ataupun dosen sendiri, untuk mengetahui bahwa keaktifan kelas berjalan dengan baik. Bagian Lecturer Services \& Class Monitoring Staff akan membuat sebuah laporan yang berisikan rasio keaktifan dosen yang mengajar di setiap kelasnya, dan laporan tersebut akan dibuat setiap bulannya. Bagian Lecturer Services \& Class Monitoring Staff akan memberikan laporan keaktifan dosen dan mahasiswa tersebut kepada Deputy Director yang bertugas untuk memastikan bahwa kelas sudah berjalan dengan baik. Deputy Director akan memberikan peringatan atau teguran bagi dosen yang tidak aktif dalam kegiatan pembelajaran di kelas. Dosen akan memberikan soal ujian kepada Bagian Thesis \& Graduation Staff. Bagian Thesis \& Graduation Staff akan melakukan penjadwalan ujian yang akan dilakukan oleh mahasiswa dan melakukan ujian berdasarkan soal ujian yang diberikan oleh dosen mata kuliah. Mahasiswa akan datang ke Binus untuk mengikuti ujian, baik itu UTS maupun UAS dan mengerjakan soal ujian. Bagian Thesis \& Graduation Staff akan memberikan jawaban ujian yang dikerjakan oleh mahasiswa kepada desen yang mengajarnya. Setelah Dosen selesai melakukan penilaian terhadap hasil ujian mahasiswanya, maka Dosen akan mengupload nilai mahasiswa ke dalam database melalui LMS. Mahasiswa dapat mengadukan keluhan-keluhan yang didapatnya di kelas maupun dengan dosen melalui Public Forum, yang di mana Public Forum ini berfungsi untuk melakukan pertanyaan ataupun keluhan mengenai dunia pembelajaran. Keluhan 
ataupun pertanyaan ini akan dapat diakses oleh Bagian Student Services \& Helpdesk Staff. Bagian Student Services \& Helpdesk Staff akan memberikan tanggapan terhadap keluhan dan pertanyaan yang diajukan oleh mahasiswa.

Tambahan mengenai mobile forum ada di sini. Mahasiswa atau dosen mengakses forum melalui mobile phone. Sistem aplikasi Android Mobile Phone akan langsung mengakses data ke System E-Learning (DB). Kemudian data forum dikirimkan ke mobile phone. Data forum sampai ke mahasiswa dan dosen. Mahasiswa mengakses dan mengunduh materi melalui mobile Android mereka masing-masing. Aplikasi Mobile Android akan mengakses server Binus Online Learning secara langsung untuk merequest meteri yang mau didownload oleh mahasiswa. Web Server akan memberikan materi sesuai dengan request yang diminta sebelumnya. Kemudian mahasiswa dapat mengunduh materi dapat membukanya melalui aplikasi di dalam mobile Android mereka. Dari database Android Mobile Phone, data forum di-update ke database Binus Online Learning.

Berikut ini adalah rich picture e-learning yang diusulkan (Gambar 4).

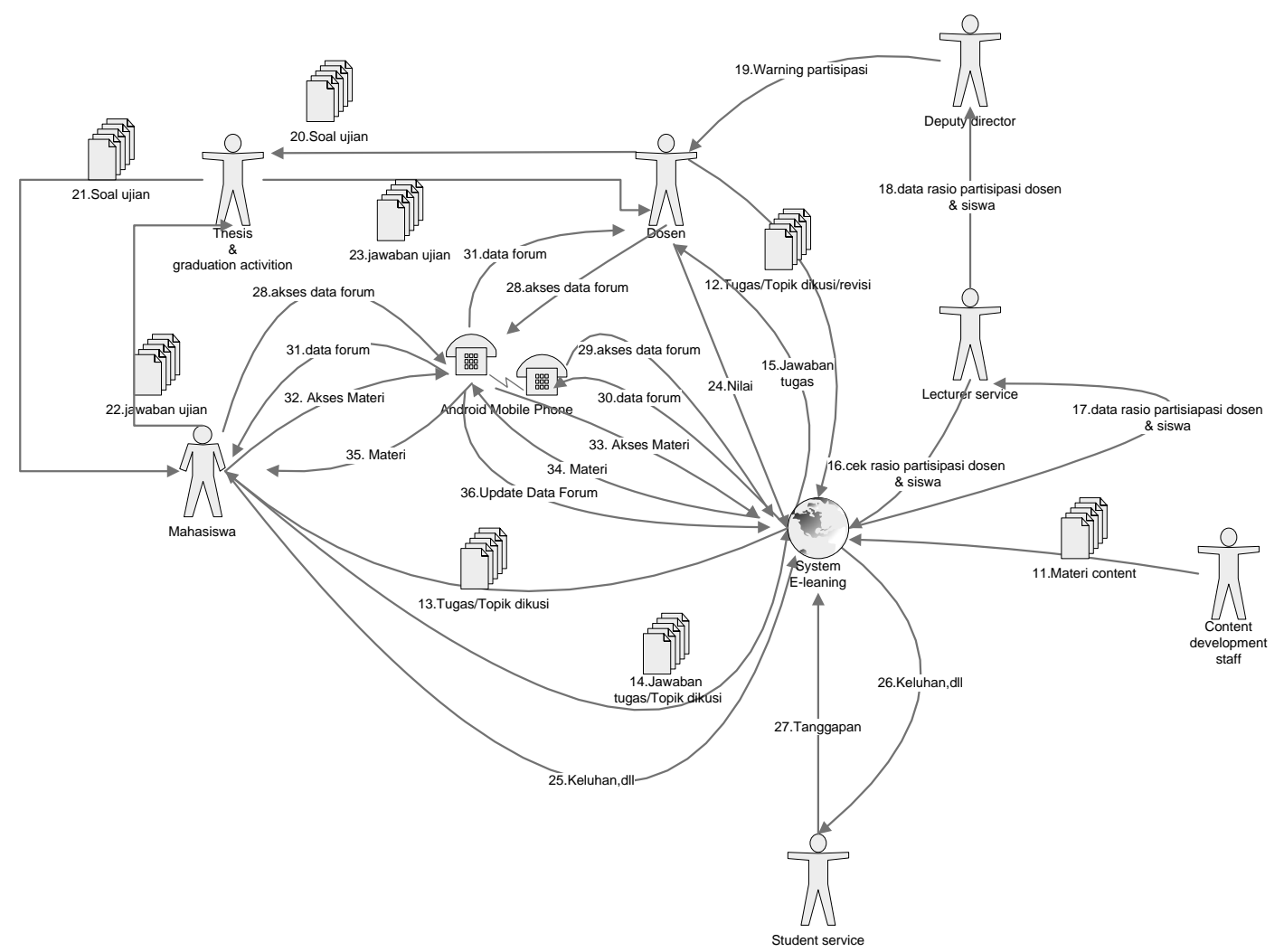

Gambar 4. Rich picture e-learning usulan.

\section{Mobile Learning Usulan}

Mahasiswa login ke Forum melalui device Android Mobile Phone. Dosen login ke Forum melalui device Android Mobile Phone. Aplikasi akan memverifikasi username dan password mahasiswa/dosen berdasarkan database Binus Online Learning.

Kemudian data forum akan dikirimkan ke-Android Mobile Phone. Mahasiswa bisa mengunduh materi masing-masing pertemuan. 
Mahasiswa memilih empat Forum yang ingin dimasuki (Class Room, Team Room, Meet The Lecture, dan Personal Room). Pada Class Room, dosen membuat topik pembahasan untuk ditanggapi oleh sesama mahasiswa. Mahasiswa juga dapat membuat topik pembahasan untuk ditanggapi oleh dosen atau oleh sesama mahasiswa. Sesama Mahasiswa bisa pula memberikan tanggapan dan pembahasan topik yang telah diberikan oleh dosen dan sesama mahasiswa. Dosen juga memberikan tanggapan dari pertanyaan atau topik yang diberikan oleh mahasiswa. Dalam Team Room, satu mahasiswa memberikan tanggapan dan bahasan untuk anggota tim yang lainnya. Sesama Mahasiswa satu kelompok mengakses bahasan yang diberikan oleh teman sekelompoknya. Anggota tim yang lain memberikan tanggapan dari bahasan yang diberikan oleh teman kelompok mereka sendiri. Mahasiswa dapat memberikan pertanyaan yang sifatnya pribadi untuk dosen yang mau dihubunginya melalui Meet The Lecturer Forum. Dosen mengakses pertanyaan dari Meet The Lecturer Forum. Dosen memberikan tanggapan dan jawaban ke Mahasiswa dari pertanyaan mahasiswa dari Meet The Lecturer Forum. Akan tetapi, mhasiswa tidak dapat mengakses Personal Room, karena Personal Room jarang digunakan oleh Mahasiswa.

Data dari masing-masing Forum akan dimasukan ke dalam Android Mobile database dahulu. Dari database Android Mobile data forum di-update ke database Binus Online Learning. Berikut ini adalah rich picture Mobile Learning yang diusulkan (Gambar 5).

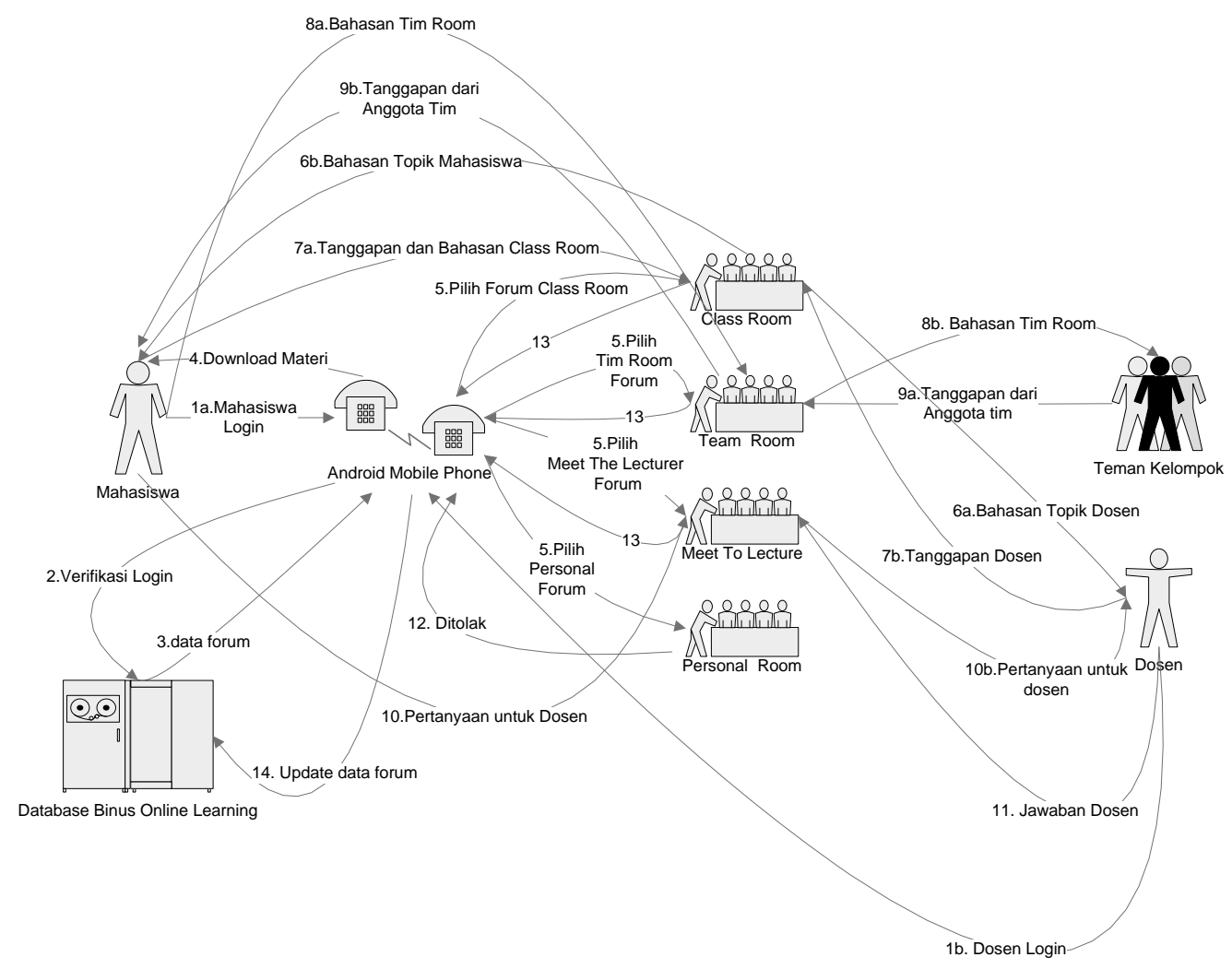

Gambar 5. Rich picture mobile learning usulan.

Catatan: 13.Data Forum

\section{Usecase Diagram}

Usecase Diagram di bawah ini (Gambar 6) menggambarkan hubungan antara actor yang terlibat dengan sistem mobile. Actor yang terlibat dalam sistem aplikasi adalah Mahasiswa dan Dosen. Relationship tersebut digambarkan dengan penggunaan garis penghubung dengan aktivitasnya. 


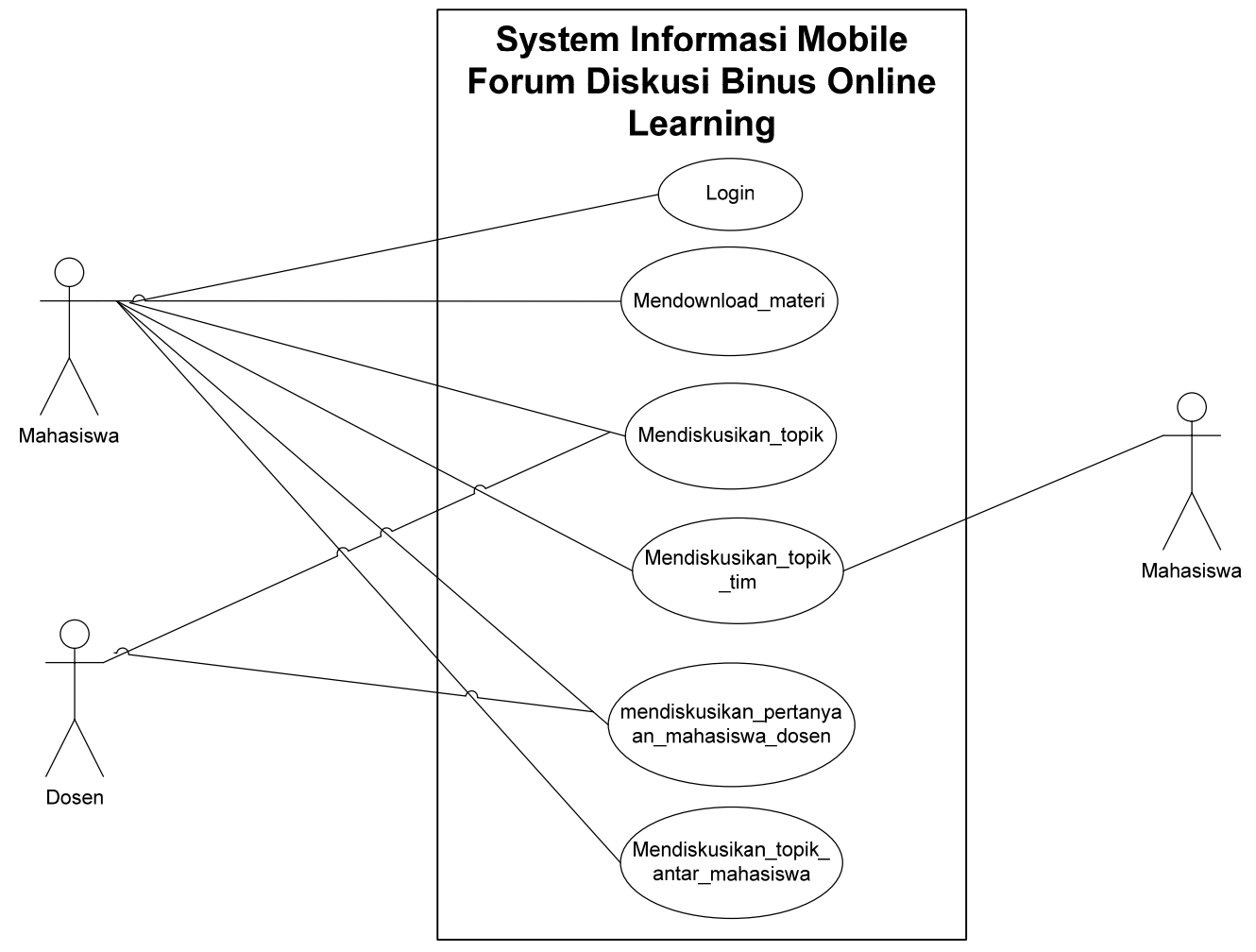

Gambar 6. Usecase diagram.

\section{User Interface}

Di mulai dari gambar login (Gambar 7), peserta melakukan login. Login yang digunakan juga sama dengan login di Learning Management System Binus Online Learning. Terdapat pula kotak yang dapat di beri tanda tick " $\sqrt{ }$ " dengan cara memberi spasi, yang digunakan jika peserta ingin selalu login pada saat mobile phone dihidupkan. Kemudian peserta memilih salah satu mata kuliah yang akan diikuti (Gambar 8). Di contoh ada tiga mata kuliah, yaitu Akuntansi Keuangan II, Akuntansi Manajemen, Pengantar Teknologi Informasi. Setelah peserta memilih mata kuliah, secara default akan masuk ke salah satu forum diskusi yaitu Class Room. Menu yang di bagian atas ditampilkan Materi, Class, Team, dan Meet The Lecturer. "Materi" untuk melihat bahan power point, sedangkan "Class" untuk masuk di forum diskusi Class Room, "Team" untuk masuk ke forum diskusi Team Room, dan "Meet the Lecturer" untuk masuk di forum diskusi meet the lecturer.

Secara default akan tampil di Class Room, berikut contoh mata kuliah Akuntansi Keuangan II, dengan dosen Heri Sukendar (Gambar 9). Di Class Room ini terdapat banyak topik sehingga akan tampil beberapa topik yang sudah dibuat. Setelah memilih salah satu topik, peserta bisa melihat thread yang ada, peserta juga bisa melakukan posting ulang (Gambar 10). Sedangkan untuk mempelajari materi, peserta dapat mengunduh power point (Gambar 11). Selain itu ada icon tambahan yang dikembangkan yaitu simbol untuk reminder (Gambar 12). Dengan tujuan memberi tanda bahwa ada informasi yang baru yang masuk ke dalam m-learning. Pada tampilan folder saat ada reminder (Gambar 13) dan tampilan mata kuliah saat ada reminder (Gambar 14), ada tanda gambar lingkaran berwarna merah dengan tanda seru "!" berwarna putih yang menunjukkan ada suatu diskusi yang masuk ke mata kuliah Akuntansi Keuangan II atau di dalam folder yang terjadi diskusi baru yang masuk. Simbol ini tidak membedakan antara diskusi yang di-posting dari mahasiswa maupun dari dosen. 


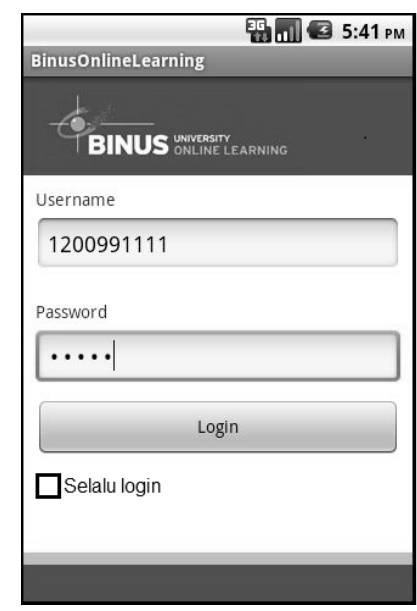

Gambar 7. Tampilan mobile Login.

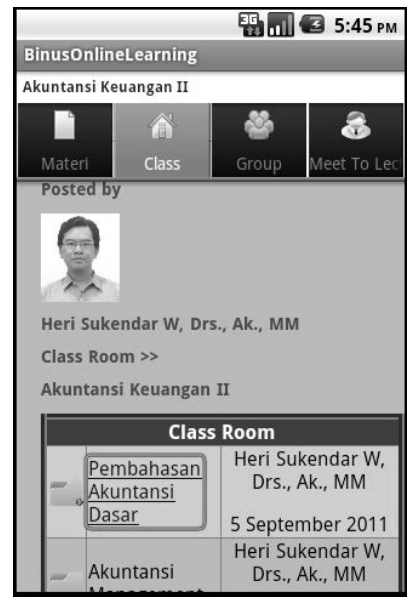

Gambar 9. Tampilan Topik.

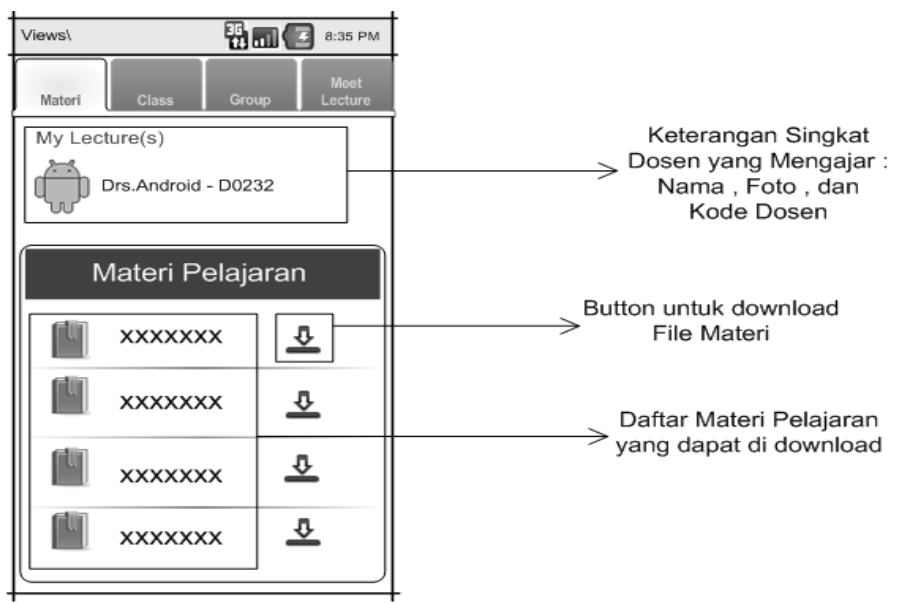

Gambar 11. Rancangan Materi.

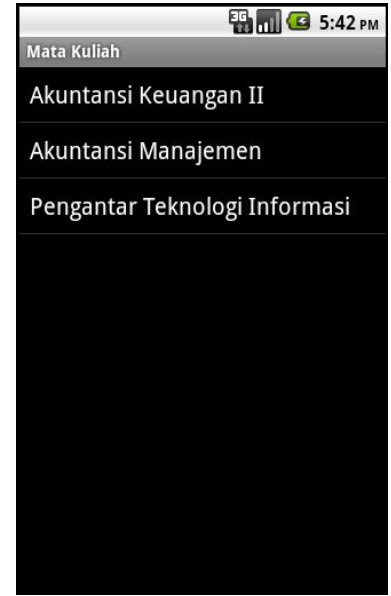

Gambar 8. Tampilan Mata Kuliah.

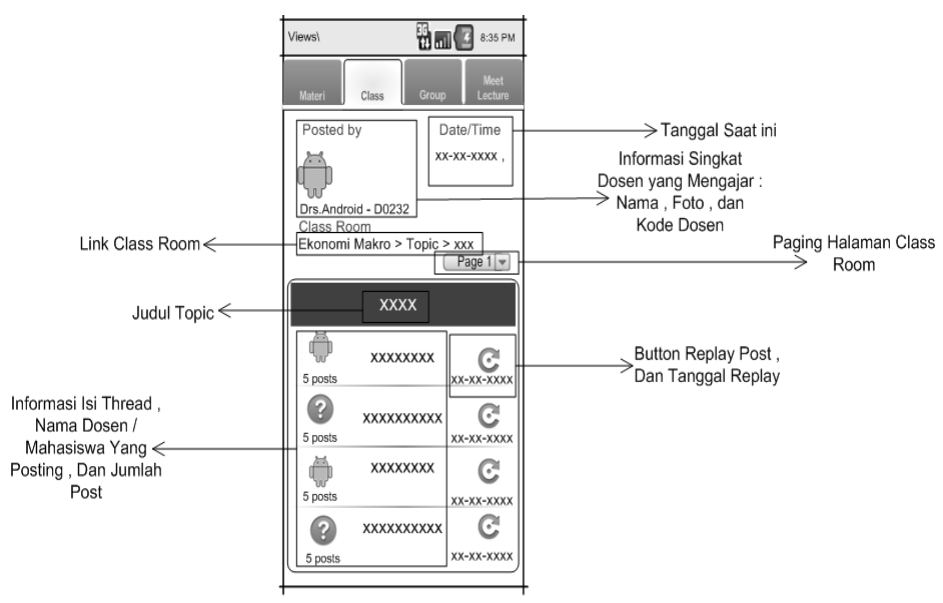

Gambar 10. Rancangan Thread.

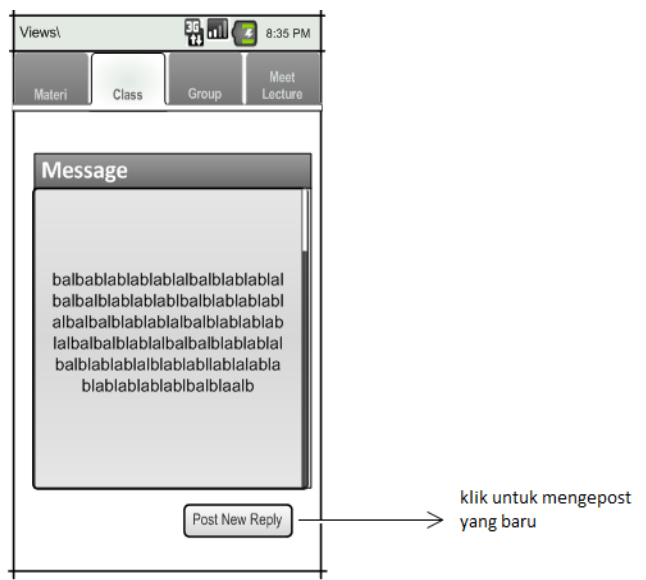

Gambar 12. Rancangan Post New Reply. 


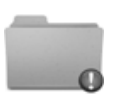

Gambar 13. Tampilan Folder saat ada reminder.

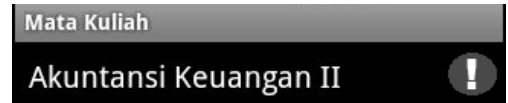

Gambar 14. Tampilan Mata kuliah saat ada reminder.

\section{PENUTUP}

Berdasarkan pembahasan yang telah diuraikan pada bab-bab sebelumnya, dapat diambil kesimpulan sebagai berikut: (1) materi presentasi diberikan dalam bentuk power point dapat dimasukkan ke dalam aplikasi m-learning. Lecturer notes tidak dapat diberikan di m-learning karena terlalu kecil dan jika diperbesar akan menjadi pecah; (2) forum diskusi yang tidak ditampilkan adalah Personal Room, karena mahasiswa tidak banyak yang mengakses Personal Room; (3) Ppsting forum diskusi dapat dilakukan di m-learning, sehingga mempermudah proses diskusi antara sesama mahasiswa, maupun dengan dosen; (4) reminder diperlukan dalam mempermudah mahasiswa maupun dosen akan adanya diskusi baru yang masuk.

\section{DAFTAR PUSTAKA}

Ally, M., Lin, F., McGreal, R. \& Woo, B. (2005). An intelligent agent for adapting and delivering course materials to mobile learners. Mobile Technology: The Future of Learning in Your Hands Conference. Diakses 27 Juni 2012 dari http://www.mlearn.org.za/CD/papers/Allyan\%20intelligent.pdf.

Andy, Yonatan. (2007). Perancangan dan Implementasi Mobile Learning untuk Pembelajaran Bahasa Jepang Berbasis Brew. Skripsi tidak diterbitkan. STEI ITB, Bandung.

Effendi, Empy \& Zhuang, Hartono. (2005). E-learning: Konsep dan Aplikasi (edisi 1). Yogyakarta: Andi Offset.

Tsai, August. An integrated e-learning solution in hospitals. Journal of Global Business Issues, 4(2). Diakses $27 \quad$ Juni 2012 dari http://proquest.umi.com/pqdweb?index $=8 \& \mathrm{did}=2198231821 \&$ SrchMode $=1 \&$ sid $=1 \& \mathrm{Fmt}=2 \&$ VInst=PROD\&VType=PQD\&RQT=309\&VName=PQD\&TS=1290947651\&clientId=68814.

Watkins, R. (2006). 75 E-Learning Activities (Making Online Learning Interactive). San Francisco: Pfeiffer. 